\title{
A MEMÓRIA DO IMIGRANTE JAPONÊS NO BRASIL E DE SEUS DESCENDENTES A PARTIR DA LITERATURA: O NIHONJIN DE OSCAR NAKASATO
}

\author{
Elton Vinicius Sadao Tada ${ }^{1}$
}

Resumo: o presente artigo pretende analisar a memória do imigrante japonês no Brasil a partir do romance Nihonjin de Oscar Nakasato. Para tanto, serão utilizadas as ferramentas da teoria da memória de Paul Ricoeur, especialmente a relação entre memória individual e coletiva e os abusos de memória. Portanto, a literatura servirá como objeto a ser estudado a partir de ferramentas filosóficas sobre memória.

Palavras-chave: Paul Ricoeur; Oscar Nakasato; Memória; Nihonjin

Abstract: the present article intend to analyze the memories of the Japanese immigrant in Brazil parting from the romance Nihonjin, of Oscar Nakasato. For this, will be used the tools of Paul Ricoeur's theory of memory, specially the relation between individual and collective memory, and the abuses of memory. Therefore, the literature will serve as object to be studied with the philosophical tools about memory.

Keywords: Paul Ricoeur; Oscar Nakasato; Memory; Nihonjin

\section{Introdução}

No Brasil, diversos membros da colônia japonesa se destacaram em suas narrativas culturais de memória. No ano de 2012, uma das mais altas honrarias

1 Mestre e doutor em Ciências da religião pela Universidade Metodista de São Paulo (UMESP), São Bernardo do Campo, Brasil. Professor da Unifamma - União das faculdades metropolitanas de Maringá - Pr. eltontada@yahoo.com.br 
da literatura nacional foi conferida ao descendente de japonês Oscar Nakasato. O prêmio Jabuti de literatura (Romance) foi atribuído ao seu romance Nihonjin.

É emblemático para o estudo de memória entender a extensão de empoderamento narrativo dado ao livro a partir dos elementos: premiação e vendagem; aceitação dos próximos (iguais); apropriação do termo Nihonjin, que é o modo de se dizer Japonês na língua japonesa, ou seja, o ícone identitário da colônia.

Com base nas discussões propostas por Paul Ricoeur sobre a memória, suas dinâmicas, suas relações com os mitos e as ideologias, bem como seus abusos, pretende-se aqui analisar a relação da narrativa de Oscar Nakasato com a memória do imigrante japonês e de seus descendentes.

\section{Os problemas da memória}

A memória, ao contrário do que se pode imaginar em lato sensu não diz respeito unicamente à recordação, documentação, história ou lembrança. Ela é uma dinâmica de hermenêutica e semiótica cultural que se constitui um fenômeno sempre atual.

No presente artigo, torna-se indispensável a prévia discussão entre memória individual e coletiva. Ao mesmo tempo em que se recorre a problemas individuais, como na narrativa sobre os protagonistas do romance Nihonjin, entende-se que tais narrativas corroboram visões da colônia e são corroboradas por ela. Nesse sentido há uma relação com a formação de identidade dos indivíduos que formam o coletivo social, ou seja, os imigrantes e seus descendentes.

\subsection{A memória entre o individual e o coletivo}

Primeiramente, é necessário que se destaque nesse ponto que quando falamos da leitura de uma obra como o Nihonjin estamos tratando não apenas com as possíveis interpretações pessoais que a mesma pode oferecer. A verdade é que existe também uma relação do indivíduo que recebe a informação com a construção social da memória. Em particular o indivíduo que pertence à colônia japonesa, ou seja, que é imigrante ou descendente, e que possui uma relação direta com a memória que é produzida em seu ambiente.

gostaria de terminar este capítulo e esta primeira parte com uma sugestão. Não existe, entre os dois pólos da memória individual e da memória coletiva, um plano intermediário de referência no qual se operam concretamente as trocas entre memória viva das pessoas individuais e a memória pública das comunidades às quais pertencemos? Esse plano é o da relação com os próximos, a quem temos o direito de atribuir uma memória distinta. Os próximos, essas pessoas que contam para nós e para as quais 
contamos, estão situados numa faixa de variação das distâncias na relação entre o si e os outros. Variação de distância, mas também variação nas modalidades ativas e passivas dos jogos de distanciamento e de aproximação que fazem da proximidade uma relação dinâmica constantemente em movimento: tornar-se próximo, sentir-se próximo. (RICOEUR, 2007, p. 141)

Pode-se notar que na relação dinâmica entre o si próprio e o outro a literatura produz um novo tipo de arquivamento, que não é findado em si, visto que é passível de diversas vozes em sua leitura, mas que dialoga tanto com aquilo que a comunidade tem produzido a seu respeito quanto com aquilo que pretende passar às próximas gerações.

Paul Ricoeur entende o problema da relação entre memória individual e coletiva a partir da resolução do conflito que se dá entre a fenomenologia da memória individual e a sociologia da memória coletiva. Nesses dois pontos entende-se como que o terceiro capítulo da primeira parte de sua obra A memória, a história, o esquecimento, consegue colocar em diálogo o pensamento fenomenológico de Husserl com a teoria da memória coletiva de Maurice Halbwachs. Pelo caminho da linguagem e de sua construção na transição entre o que é individual e o que é coletivo, Ricoeur mostra que a superação entre a memória individual e a coletiva se dá na reorganização dos sujeitos, pensando-se além do "eu" versus o "outro", acrescentando o elemento que está entre, o "próximo". Assim, constitui-se a memória no âmbito do eu, dos próximos e dos outros (RICOEUR, 2007, 142).

A narrativa memorativa do imigrante japonês e de seus descendentes pode envolver tanto a concepção coletiva de "outros" como a de "próximos" para aqueles que o fazem a partir de identificação linguística. É justamente na separação entre os próximos e os outros que se busca entender os possíveis abusos de memória contidos no livro Nihonjin de Nakasato.

No epílogo do livro Nihonjin lê-se:

Yu batake Kuwa wo tomerazu

Oya no te wo miiru kodomo ni

Tasogare fukashi

O lusco-fusco aprofunda

A figura do menino olhando

As mãos do pai

Que não larga a enxada (NAKASATO, 2011, p.7)

Chama atenção o formato como o texto é citado por Nakasato. Primeiramente se encontra a transliteração do poema japonês que vem seguido de sua tradução ao 
português. Infere-se daí que o autor não deseja se comunicar apenas com quem sabe ler o japonês nem com aqueles que dominam apenas a língua portuguesa. Antes, ele pretende se comunicar com quem entende o japonês transliterado, alcançando sobretudo o descendente de japonês.

Antes que se comecem as discussões propriamente ditas sobre o Nihonjin de Nakasato é importante que se entenda o seguinte pressuposto: "Hideo era uma ponte firme que levava seus filhos ao Japão. Ponte de concreto, construído ao longo dos anos, com pilares grossos fincados na terra, sobre a água turva" (NAKASATO, 2011, p. 93)

O romance narra integralmente a história de Hideo, e é ao redor dele que ocorrerão todas as discussões ${ }^{2}$.

O caminho aqui escolhido para direcionar a crítica é algo que deve ser bem especificado para que não haja dúvidas sobre a estrutura metodológica que sustenta o trabalho. Uma vez tendo sido escolhida a prática do labor relacional, tendo na literatura uma voz para nutrir o diálogo sobre a temática da memória, entende-se que é preponderante que se escolha o tópico trazido de Ricoeur sobre abusos de memória para que tal contato seja feito, ou seja, é nesta centelha que se pretende acender a chama.

Quando se trata de memória de um grupo cultural específico o tópico sobre a identidade não pode ser suprimido. No entanto, ele não se faz aqui central, sendo mais importante que se discutam as questões sobre a memória do coletivo do imigrante japonês ${ }^{3}$ e seus descendentes em geral, bem como sobre os abusos de memória na narrativa literária de Nakasato.

\begin{abstract}
Como causa primeira da fragilidade da identidade é preciso mencionar sua relação difícil com o tempo; dificuldade primária que, precisamente, justifica o recurso à memória, enquanto componente temporal da identidade, juntamente com a avaliação do presente e a projeção do futuro. Ora, a relação com o tempo cria dificuldades em razão do caráter ambíguo da noção do mesmo, implícita na do idêntico. De fato, o que significa permanecer o mesmo através do tempo? Já enfrentei, no passado, esse enigma, para o qual propus distinguir dois sentidos do idêntico: o mesmo como idem, same, gleich - o mesmo como ipse, self, selbst. (RICOEUR, 2007, p. 94)
\end{abstract}

2 Ver Anexo I.

3 Parece haver precedentes em relação à estrita manutenção da memória, principalmente no âmbito da moral e dos costumes: "na era Meiji (1868-1912), ao introduzir os hábitos ocidentais, não foram desprezados os costumes e as tradições do povo. Uma preocupação sempre presente foi a manutenção dos próprios valores éticos, culturais e históricos" (PASSINI, 1995, p.75). 
Há um trecho no romance Nihonjin que bem expressa a questão da identidade. Essa passagem narra a prisão do Ojiichan ${ }^{4}$ por conta de sua nacionalidade japonesa na ocasião da segunda grande guerra:

\begin{abstract}
Minha prisão foi uma arbitrariedade - disse ojiichan. Havia a guerra, e as pessoas pareciam estar enlouquecendo. Sempre entendera a cadeia como punição para quem matava ou roubava, era o que não se podia fazer no Brasil ou no Japão, em qualquer lugar, e então a polícia começava a prender nihonjin porque nihonjin era nihonjin. Ojiichan disse que em São Paulo a Superintendência de Segurança Política e Social publicara uma portaria que tornara um inferno a vida dos japoneses, bem como de italianos e alemães. (NAKASATO, 2011, p.88)
\end{abstract}

É notório o fato da narrativa trazer a formulação da sentença do exato modo como se pode entender o princípio da identidade aristotélica: "a polícia começava a prender Nihonjin porque Nihonjin era Nihonjin". Nesse sentido, por mais que não haja um discurso sobre a identidade, há uma forte evocação de que é por conta dela que se davam as situações que eram reclamadas. Na formulação "prender Nihonjin porque Nihonjin era Nihonjin" a primeira e a segunda vez em que em que o termo Nihonjin é utilizado diz respeito a percepção identitária que o próprio Ojiichan está narrando. Já o terceiro Nihonjin diz respeito ao elemento coletivo, cultural, à nacionalidade, ao fato de existir um grupo específico de pessoas provenientes do Japão.

Além da importante noção de identidade supracitada, o Nihonjin nos mostra a compreensível noção de preocupação com a alteridade. Recorrendo mais uma vez às palavras de Ricoeur:

A segunda causa de fragilidade é o confronto com outrem, percebido como uma ameaça. É um fato que o outro, por ser outro, passa a ser percebido como um perigo para a identidade própria, tanto a do nós como a do eu. Certamente isso pode constituir uma surpresa: será mesmo preciso que nossa identidade seja frágil a ponto de não conseguir suportar, não conseguir tolerar que outros tenham modos de levar sua vida, de se compreender de inscrever sua própria identidade na trama do viver-juntos, diferentes dos nossos? (RICOEUR, 2007, p.95)

Exemplo de tal ação na obra de Nakasato se vê quando ele afirma que:

Hideo não insistiu mais. Despediu-se educadamente, curvando as costas, mas sem cordialidade, porque aquela mulher, tal como a preta que curara Kimie na Fazenda

4 Termo japonês para avô.

5 Ver: Cinema, aspirinas e urubus. 
Ouro Verde, lembrava-lhe que estava em terra estrangeira e que gaijin, na verdade, era ele. (NAKASATO, 2011, p. 70)

Em tal ocasião Hideo estava pedindo para a professora de seu filho Haruo que não o ensinasse que ela era brasileiro, mas sim japonês. Além de não ter seu pedido atendido teve que se defrontar com a realidade que ele estava agora em terras que não lhe pertenciam, ou seja, que era estrangeiro.

Ainda em relação à temática da alteridade pode-se ver o seguinte exemplo:

Por isso, nihonjin precisa se manter sempre junto de nihonjin - predicou Hideo, que nunca dizia por dizer, porque as palavras não foram inventadas para serem desperdiçadas. - No meio de gaijin, um nihonjin sozinho é fraco, é uma vara fácil de ser quebrada. Não estamos no Japão, e aqui no Brasil a gente não sabe em quem pode confiar. Mas, se nos mantivermos juntos, seremos um feixe, e ninguém poderá nos quebrar. (NAKASATO, 2011, p. 61)

Deve ser notado que a justificativa que compõe o argumento de Hideo a seu filho sobre a necessidade de união dos nihonjin diz respeito diretamente à estranheza das demais pessoas, ou seja, é um meio de defesa ante a uma realidade hostil.

$\mathrm{O}$ terceiro momento tratado por Ricoeur como uma fragilidade da memória é a violência que funda a mesma. No caso do imigrante japonês e de seu descente tal processo não se faz diferenciado.

\begin{abstract}
A terceira causa de fragilidade é a herança da violência fundadora. É fato não existir comunidade histórica alguma que não tenha nascido de uma relação, a qual se pode chamar de original, com a guerra. O que celebramos com o nome de acontecimentos fundadores, são essencialmente atos violentos legitimados posteriormente por um Estado de direito precário, legitimados, no limite, por sua própria antiguidade, por sua vetustez. [...] é assim que se armazenam, nos arquivos da memória coletiva, feridas reais e simbólicas (RICOEUR, 2007, p. 95)
\end{abstract}

O término da segunda guerra mundial, algo de extremo valor para a religiosidade japonesa, é tratado sutilmente por Nakasato em sua obra. Tal posicionamento é compreensível quando se nota que existem diversos sentimentos sócio-político-religiosos que envolvem tal discussão. Mesmo assim, deve-se notar que não tratar ou tratar levemente de um assunto faz com que as noções de esquecimento sejam evocadas.

E o artigo de Haruo foi publicado:

Foi com grande tristeza que os japoneses do mundo inteiro ouviram a Declaração da Condição Humana do imperador Hiroíto, que assumiu publicamente não ser uma divindade, e sim um ser humano, filho de seres humanos, o imperador Taisho e a 
imperatriz Sadako. [...] para aqueles que ainda não aceitaram a rendição japonesa e sustentam a ideia da vitória do Japão na Segunda Guerra mundial, este é o momento de se fazer uma reflexão. (NAKASATO, 2011, p. 135)

A segunda guerra mundial foi um elemento especialmente marcante para os descendentes de japoneses que vivenciaram sua infância ou adolescência em tal período, pois a eles foi destinado um locus fronteiriço de difícil experimentação. Por um lado eram pequenos brasileiros que cresciam, se desenvolviam e eram educados nesse país. Por outro lado, eram filhos de japoneses e conservavam suas características, costumes e cultura, de modo que eram vívidos exemplos de pessoas que os brasileiros combatiam na guerra. Esse elemento é de uma tensão suficientemente ríspida para gerar conflitos tanto dentro da comunidade quanto da sociedade em geral. Este assunto será retomado adiante pra que se entenda sua relação com a religiosidade.

\section{Os abusos de memória}

Alguns abusos de memória podem ser notados em relação a uma personagem cuidadosamente construída por Oscar Nakasato. O narrador conta a história de seu Ojiichan e de sua OBachan ${ }^{6}$. Entretanto, antes de ter se casado com a Obachan do narrador, o personagem principal teve outro casamento. Nesse primeiro relacionamento conviveu com uma mulher fraca e frágil. As características dela chamam atenção e até mesmo podem gerar pena e compadecimento por parte dos leitores.

Há um elemento que inicialmente pode ser considerado bastante subversivo na narrativa do Nihonjin. A primeira esposa do Ojiichan sofre muito para se adequar à realidade do trabalho braçal na lavoura brasileira. Em meio a tanta dor e sofrimento acaba se relacionando com um amigo do Ojiichan, e o "trai" através de uma relação sexual.

A noção de sexualidade enquanto tópico de discussão não parece ser algo comum ou bem-vindo no interior do ambiente da colônia. Muito além disso, existia a impossibilidade de aceitar algo como uma traição marital, que seria suficiente para gerar grande desconforto. Ao tratar de tal assunto em uma narrativa com tanto potencial de construção de memória quanto o Nihonjin, Nakasato tende a exceder os códigos morais que regem a dinâmica das lógicas narrativas para tal coletivo. Entretanto, de maneira sutil e pouco perceptível há uma virada significativa na situação da personagem que comete a traição. Em determinado momento ela acaba vendo neve nos cafezais do interior paulista, e morre em meio a tal demência.

6 Avó. 
Tal personagem não é acusada pelo narrador de ter cometido algum crime, nem mesmo de ter desrespeitado a moral de seu grupo, mas sua participação na narrativa é concluída com a loucura, a morte, e o fato de não ter gerado filhos. Esses três elementos são de carga notável de expressão, e carregam consigo uma lógica causal implícita que não podem ser ditas pelas palavras do narrador, mas que não tardam a ser mostradas na lógica da completude da obra.

Uma noite, e era a noite mais fria do ano, Kimie não conseguiu dormir. Estava doente. Tomara os chás de Maria, ficara quieta sob as suas mãos enquanto ela rezava aquelas rezas que não entendia, mas não melhorara. De madrugada aumentou a febre. Quis ver a neve. Hideo roncava ao seu lado. Levantou-se, caminhou até a porta da sala e a abriu. A neve cobria a terra. Saiu, correu até o cafezal, correu entre os pés de café, sentindo a neve cair sobre a sua cabeça, sobre os seus ombros. Correu durante muito tempo, estrela do espetáculo, abrindo os braços, ela, que sempre preferiu ficar na janela. Finalmente, quando se cansou, sentou-se na terra fria. A morte chegou lentamente. Há quanto tempo morria? Tranqüila, congelada pela neve, congelada pelo sol. (NAKASATO, 2011, p. 43)

Nesse ponto deve-se recorrer à explicação de Ricoeur que nos mostra que:

\begin{abstract}
A ideologização de memória é possibilitada pelos recursos de variação que o trabalho de configuração narrativa oferece. As estratégias do esquecimento enxertam-se diretamente nesse trabalho de configuração: pode-se sempre narrar de outro modo, suprimindo, descolocando as ênfases, refigurando diferentemente os protagonistas da ação assim como os contornos dela. [...] o recurso à narrativa torna-se assim a armadilha, quando potências superiores passam a direcionar a composição da intriga e impõem uma narrativa canônica por meio de intimidação ou de sedução, de medo ou de lisonja. (RICOEUR, 2007, p. 455)
\end{abstract}

Baseado em tais afirmações, pode-se inferir que há um abuso de memória pela via da ideologização com amplo domínio da configuração narrativa. Entendese que o caso de problemas conjugais e relações afetivas e sexuais extra-maritais não são extintas de nenhum grupo, de nenhuma sociedade. Mesmo assim, a forma como o caso específico de Kimie, a primeira esposa do Ojiichan, é tratado, mostra que há um cuidado para que se conserve a narrativa sobre o imigrante japonês de tal ou qual forma ${ }^{7}$.

7 Outro exemplo de como se dava as relações de Hideo com seus se mostra: "quando todos estavam reunidos, disse que era um pai benevolente, que se esforçava para manter os filhos unidos sob algumas normas [...] disse que Haruo há muito tempo desafiava a sua autoridade, e por isso decidira por punição severa: ficaria em kinshin, uma semana fora de casa, com a roupa e um par de sandálias. Poderia dormir com os bichos na tulha, comer o que encontrasse no pomar [...] que ninguém abrisse a porta para ele, que ninguém lhe desse nada para comer, pois se alguém o fizesse também seria penalizado. Disse que Haruo teria tempo suficiente para refletir e retornaria arrependido" (NAKASATO, p. 76) 


\title{
Vale notar a relação de tal ponto específico com um texto mitológico japonês
} antiquíssimo, o Kojiki:

\begin{abstract}
Izanami já não via Izanagi da mesma maneira: ela fascinada pela sua beleza, presença e força. Ela pediu-o então em casamento. Ele aceitou sem hesitar. Tudo poderia ter sido perfeito, mas o nascimento do seu primeiro filho trouxe os primeiros problemas. Esse tinha nascido sob a forma de um horrível verme. Os dois abandonaram a abominação numa barca feita de canas de bambu. A segunda criança foi igualmente monstruosa. Decidiram então interrogar os Kamis. Para tal, eles deveriam voltar para o reino implantado na via láctea: Takamanohara. $\mathrm{O}$ casal mais antigo explicou-lhe que o seu casamento era a fonte de infelicidade: Com efeito, apenas Izanagi podia pedir em casamento a deusa e não o contrario. Os dois subsistiram então no lugar dos Deuses. Porém os dois encontravam-se muito infelizes e já não se falavam. $\mathrm{O}$ tempo passou e Izanami recordou a época maravilhosa do início do seu amor. Ela correu então para regressar a sua pequena ilha. Izanagi viu-a e considerou-a tão bela e radiosa que não tardou a segui-la.

O pequeno pedaço de terra era agora vestido de um luxuoso manto de verdura. Izanagi sentia-se renascer do seu amor reencontrado e pediu Izanami em casamento. Fez-lhe um grande sorriso e os dois voltaram a casar.

A maldição foi levantada. Os seus primeiros filhos foram primeiro ilhas: A primeira Awaji, a segunda Shikoku, Oki, Kyûshû, Tsuhima, Honshû e Hokkaido. Seis novas ilhas nasceram a seguir, seguidas por mais de 3000 pequenas ilhas. Foi assim que nasceu o Japão chamado na altura Wakoku (KOJIKI, cap. 1).
\end{abstract}

Tal narrativa mitológica japonesa ${ }^{9}$ é a mesma que garantia ao imperador a posição de descendente direto da divindade, ou seja, de face divina na terra. Tal culto ao imperador permaneceu durante diversas dinastias, sendo parcialmente suprimida apenas na ocasião da derrota do Japão na segunda guerra mundial. Quando o imperador japonês admitiu a derrota ante aos ataques nucleares, abriu também sua mão, deixando de ostentar a posição de divindade. Ao abrir mão de seu status divino, o imperador Hirohito obrigou os japoneses a resignificarem elementos tais

8 Sobre o Kojiki é importante notar que: "a tradição mítica do pensamento japonês provém da época préhistórica. No ano 712, Oono Yasumaro faz a primeira compilação de mitos e lendas que nos permitem ver essa mentalidade mítica em sua forma primitiva. Nesse primeiro livro, intitulado Koyiki (recordações dos acontecimentos antigos), Yasumaro introduz as tradições orais de mitos e lendas preexistentes. Manifestamse nele vários aspectos da tradição mítica, elementos determinantes do caráter do pensamento japonês." (OSHIMA, 1991, p. 25)

9 "na mitologia de Koyiki não há uma clara distinção entre o divino e o humano; antes, o divino e o nãodivino são considerados como duas funções diferentes do mesmo ser. Esta é uma ambiguidade que se projeta ao longo de toda a história do pensamento japonês, e esta preferência se manifesta pela primeira vez na antologia Koyiki" (OSHIMA, 1991, p. 28) 
como os samurais ${ }^{10}$, os sumotori ${ }^{11}$, dentre outros que estavam diretamente ligados à religiosidade japonesa.

Nesse momento pode-se recorrer à opinião do filósofo japonês Hitoshi Oshima: "creio que podemos concluir pelo menos o seguinte: a história do pensamento japonês é inconcebível se não levarmos em consideração a persistência da mentalidade mítica do povo japonês." (OSHIMA, 1991, p. 137). Nesse sentido, talvez a forma como a memória japonesa seja evocada pelo imigrante e seus descendentes possa ser uma maneira de conservar o mito, bem como a forma mítica de pensar o cosmos. Vale ainda uma consideração breve de Claude Lévi-Strauss:

Talvez porque sua história escrita se inicie em data relativamente tardia, os senhores a enraízam muito naturalmente em seus mitos. A passagem se opera suavemente, e com mais facilidade ainda na medida em que o estado em que lhes chegaram esses mitos atesta, por parte dos compiladores, uma intenção consciente de fazer deles um prelúdio à história propriamente dita. (LÉVI-STRAUSS, 2012, p. 16)

As consequências de tais ações foram sentidas na colônia japonesa do Brasil. Já no processo de produção de memória existem narrativas como a conhecida "corações sujos"12 que conta o levante dos colonos contra seus compatriotas que aceitavam a derrota na guerra.

Ele (Haruo) olhou o pai, que estava impassível em um canto da sala, caminhou lentamente em direção ao homem que segurava a bandeira e a adaga, levantou as mãos para pegá-las, mas em vez de fazê-lo, empurrou-o com força e correu para a porta. Não cometeria haraquiri, não tinha feito nada de que se arrependesse ou de que se envergonhasse, não era nenhum criminoso. Morreu ainda na varanda, atingido por dois tiros disparados por dois tokkotais que estavam à espreita (NAKASATO, 2011, p. 158)

Já nos momentos conclusivos do romance de Nakasato encontra-se uma afirmação bastante relevante para a proposta do presente texto:

- Ojiichan, quer que eu lhe envie alguma coisa do Nihon?

- O que eu posso querer do Nihon?

- É furusato de ojiichan.

10 Guerreiros japoneses devotos do imperador.

11 Ao sumotori cabia a guarda pessoal do imperador.

12 O próprio protagonista d história de Nakasato havia se filiado ao grupo que daria origem aos corações sujos. “- eram tempos difíceis - lembrou ojiichan. Por isso se associara à Shindo Renmei, a Liga do Caminho dos Súditos." (NAKASATO, p. 91) 
Ele levantou os olhos.

Furusato... O meu furusato não existe mais (NAKASATO, 2011, p. 169).

Em última análise, parece que nem todos os imigrantes e seus descendentes chegam à mesma conclusão que Hideo chegou sobre seu Furusato ${ }^{13}$. Pelo contrário, parece que o Japão pré-guerra foi trazido ao Brasil na memória do imigrante e sobrevive hoje melhor aqui do que lá, pois muitas das memórias aqui produzidas são compreendidas em sentido diverso daquele que se constrói na atual realidade japonesa.

\section{Conclusão}

Após a análise aqui feita podemos notar alguns elementos que devem ser destacados. A religiosidade japonesa é um ponto marcante no comportamento do imigrante e de seus descentes. Todavia, isso não se dá a partir de um processo que se separa dos elementos culturais que regem a conduta dos membros de tal grupo.

A construção coletiva da memória pode ser examinada por diversas vias. Para o trabalho aqui proposto elegeu-se entender como os abusos de memória e esquecimento podem ser elementos significativos em tais processos. A forma como a literatura de Nakasato trata os personagens bem como lógica causal que os acompanha é sintomática em tal sentido.

O Nihonjin de Nakasato possui uma conduta e uma historia que corroboram a ideia de uma identidade japonesa similar àquela notada no país nos primeiros anos do século passado, ou seja, com a ideia religiosa fortemente vinculada à pessoa do imperador através de sua herança divina.

Em nossos dias, muitos anos depois da significante renúncia do imperador à entronização divina, existem ainda elementos que não foram atualizados pelas famílias que deixaram seu país de origem antes do fim da segunda guerra mundial e que não regressaram. A colônia japonesa no Brasil é uma amostra de como a memória cultural transpassa fronteiras espaço-temporais para se formatar dentro de uma comunidade que a conserva a partir de suas narrativas. Em termos resumidos, poderíamos questionar de maneira astuta se a ideia do japonês contido nas narrativas do imigrante japonês e de seus descentes, incluindo o próprio Nihonjin de Nakasato, pode ser comparada com as noções presentes no coletivo do japonês que não saiu do Japão e que vivenciou todas as mudanças socioculturais que o país experimentou na segunda metade do século passado. Tal fato parece ser aprioristicamente pouco provável. Pode-se questionar ainda se os abusos de

13 Vila. Local de onde se provém. 
memória cometidos na narrativa literária como no caso do livro Nihonjin são justamente tentativas de resgatar a memória e a identidade do japonês do período pré-guerra, dando assim aporte para a construção da memória e da identidade de seus descendentes que permaneceram no Brasil.

\section{Bibliografia}

LÉVI-STRAUSS, C. A outra face da lua: escritos sobre o Japão. São Paulo: Cia das letras, 2012.

MORAES, W. Fala a lenda japonesa. Lisboa: cotovia, 1993.

NAKASATO, Oscar. Nihonjin. São Paulo: Benvirá, 2011.

OSHIMA, Hitoshi. O pensamento japonês. Coleção ensaios: filosofia. São Paulo: Escuta, 1991.

PASSINI, E. Y. Japão: que país é este? Minas Gerais: lê, 1995.

RICOEUR, P. A memória, a história, o esquecimento. Campinas: Unicamp, 2007.

\section{Anexo I}

Árvore genealógica do personagem Hideo.

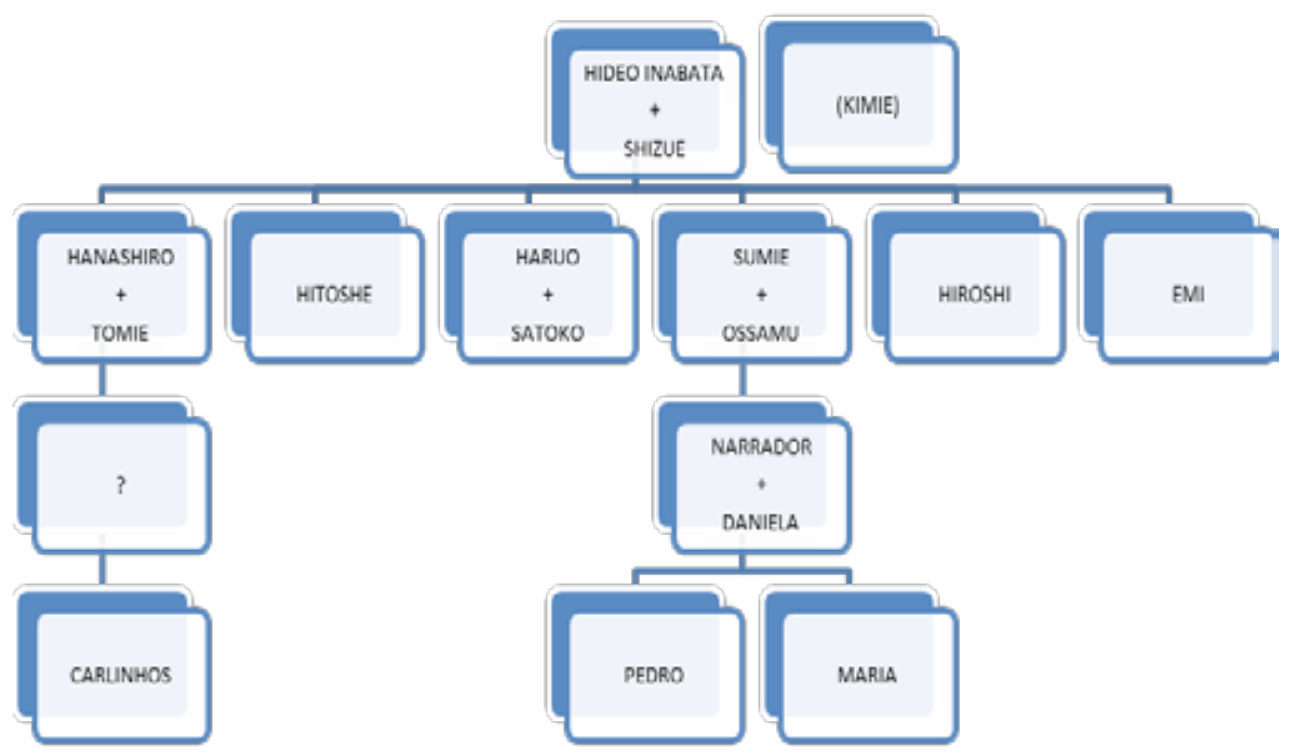

